\title{
Trait mindfulness is associated with lower pain reactivity and connectivity of the default mode network
}

DOI:

10.1016/j.jpain.2018.10.011

Document Version

Accepted author manuscript

Link to publication record in Manchester Research Explorer

\section{Citation for published version (APA):}

Harisson, R., zeidan, F., Kitsaras, G., ozcelik, D., \& salomons, T. (2018). Trait mindfulness is associated with lower pain reactivity and connectivity of the default mode network. The Journal of Pain. https://doi.org/10.1016/j.jpain.2018.10.011

\section{Published in:}

The Journal of Pain

\section{Citing this paper}

Please note that where the full-text provided on Manchester Research Explorer is the Author Accepted Manuscript or Proof version this may differ from the final Published version. If citing, it is advised that you check and use the publisher's definitive version.

\section{General rights}

Copyright and moral rights for the publications made accessible in the Research Explorer are retained by the authors and/or other copyright owners and it is a condition of accessing publications that users recognise and abide by the legal requirements associated with these rights.

\section{Takedown policy}

If you believe that this document breaches copyright please refer to the University of Manchester's Takedown Procedures [http://man.ac.uk/04Y6Bo] or contact uml.scholarlycommunications@manchester.ac.uk providing relevant details, so we can investigate your claim.

\section{OPEN ACCESS}


Trait mindfulness is associated with lower pain reactivity and connectivity of the default mode network

Richard Harrison, Fadel Zeidan, Georgios Kitsaras, Dila Ozcelik, Tim V. Salomons

PII:

DOI:

Reference:

$$
\text { S1526-5900(18)30910-6 }
$$

https://doi.org/10.1016/j.jpain.2018.10.011

YJPAI 3661

To appear in:

Journal of Pain

Received date:

Revised date:

Accepted date:
13 July 2018

26 October 2018

30 October 2018

Please cite this article as: Richard Harrison, Fadel Zeidan, Georgios Kitsaras, Dila Ozcelik, Tim V. Salomons, Trait mindfulness is associated with lower pain reactivity and connectivity of the default mode network, Journal of Pain (2018), doi: https://doi.org/10.1016/j.jpain.2018.10.011

This is a PDF file of an unedited manuscript that has been accepted for publication. As a service to our customers we are providing this early version of the manuscript. The manuscript will undergo copyediting, typesetting, and review of the resulting proof before it is published in its final form. Please note that during the production process errors may be discovered which could affect the content, and all legal disclaimers that apply to the journal pertain. 


\section{Highlights}

- We examine trait mindfulness in mindfulness-naïve individuals

- Trait mindfulness is associated with high pain threshold and low catastrophizing

- Default mode network and somatosensory cortices are decoupled in mindful individuals

- This decoupling is associated with adaptive pain responses 


\title{
Trait mindfulness is associated with lower pain reactivity and connectivity of
} the default mode network

\author{
Richard Harrison', Fadel Zeidan, Georgios Kitsaras ${ }^{1}$, Dila Ozcelik ${ }^{1}$, Tim V. \\ Salomons ${ }^{1,3^{*}}$,
}

1. University of Reading, School of Psychology and Clinical Language Sciences, Reading, UK

2. Wake Forest School of Medicine, Winston Salem NC, USA

3. Queen's University, Department of Psychology, Kingston, ON, Canada ${ }^{*}$ Corresponding Author

25 pages; 6 figures, 1 table

\section{Disclosures}

- Richard Harrison's studentship is funded by a joint UK National Health ServiceUniversity of Reading CASE studentship.

- Tim Salomons was funded by a Marie Curie International Incoming Fellowship and a British Academy/Leverhulme Small Grant.

- Fadel Zeidan was funded by a National Center for Complementary and Integrative Health grant and a Mind and Life Institute Grant.

- No conflict of interest is represented within these sources of funding. 
Abstract: Mindfulness-based training reduces pain in clinical and experimental settings. Evidence suggests these beneficial effects are facilitated via increased focus on the present moment, and reduced emotional enhancement of pain. The majority of the existing literature has focused on mindfulness as a learned skill, and on the neural mechanisms that underlie the acquisition of this skill. It is unknown whether similar mechanisms are associated with trait mindfulness in the absence of training and whether these mechanisms confer the ability to cope with pain. To determine this, we measured trait mindfulness and pain responsivity in 40 healthy volunteers naive to mindfulness meditation. As a feature of interest, we targeted the default mode network (DMN); a network of interacting brain regions associated with processes such as introspective thought, mind-wandering and rumination. As extant studies have implicated the default mode network (DMN), in the beneficial effects of mindfulness, we examined resting state connectivity of the precuneus, a core DMN node. Higher trait mindfulness was associated with higher pain thresholds $(r=.43, p<.01)$ and lower pain catastrophising $(r=-.51, p<.01)$. Consistent with the neural mechanisms of trained mindfulness, higher trait mindfulness was associated with lower connectivity between nodes of the DMN. It was also associated with higher connectivity between the DMN and somatosensory cortices. These findings are consistent with processes taught in formal meditation training, namely increased focus on sensory experience and decrease in emotional appraisal processes, indicating that behavioural and neurological mechanisms described in the interventional mindfulness literature also underlie trait mindfulness prior to any formal training.

Perspective: Mindfulness research mostly focuses on mindfulness as a trained skill, rather than a trait. Consistent with trained-mindfulness studies, we demonstrate mindfulness is associated with variations in neural connectivity linked to sensory \& evaluative processes. These findings indicate that trait mindfulness serves as a marker for individual differences in pain coping 


\section{Introduction}

Mindfulness training reduces pain in clinical and laboratory settings $[10,24,34,41,53,60]$. Similarly, long term meditative practice mitigates sensory [17-19] and emotional $[8,16,37]$ components of pain. Several studies have shown that mindfulness attenuates pain by enhancing attentional focus on the present moment and regulating associated emotional responses $[4,31,43]$. A growing body of work documents neural activations associated with the effects of mindfulness training on pain. Decreases in pain following mindfulness-based training are frequently associated with greater activation in brain areas associated with sensory and/or salience processing [16,32,61], alongside decreases in the prefrontal cortical regions linked to evaluative and/or emotional responses [21,57].

These neural findings suggest that mindfulness alters pain through a unique mechanism simultaneously involving increased attention to sensory input but reduced evaluative and negative affective responses [42,43,62]. Growing evidence demonstrates that training of attentional focus is accompanied by altered activation in areas related to cognitive control and, in particular, brain networks supporting self-referential processing, such as the default mode network (DMN) [13,28,57,61]. Trained mindfulness is associated with decreased activation across DMN nodes (including the medial prefrontal cortex (mPFC) and precuneus) following both short term ( $<1$ month) mindfulness-based interventions [14,15] and long term meditative practice [7,52]. These findings have been interpreted in terms of a top-down control of ruminative and self-referential processes[15,52]. While these associations have been extensively documented in studies of mindfulness training [59], little is known about the neural mechanism of untrained dispositional mindfulness and its potential role in pain reactivity.

Higher dispositional mindfulness is associated with lower chronic pain severity $[33,35,38]$, lower frequency of rumination [36] and lower levels of pain catastrophising [40]. Determining the neural mechanisms that underlie these differences can provide key insight into why 
some individuals appear to be intrinsically vulnerable to pain while others seem to possess innate protective mechanisms.

Here we investigate whether untrained trait mindfulness is associated with differential responses to pain stimuli prior to any meditative training, and whether these intrinsic differences reflect differential patterns of resting state functional connectivity. Based on previous work $[9,19,37,42,58]$, we hypothesize that individuals high in trait mindfulness will have higher pain thresholds and lower emotional reactivity to pain. Secondly, consistent with mindfulness training studies, higher trait mindfulness will be associated with lower intrinsic default mode connectivity $[7,20,51]$ consistent with a reduced tendency towards ruminative processes [12]. Finally, individual differences in pain coping behaviour will be associated with higher connectivity between attentional and sensory/salience regions, consistent with elevated attention to the ongoing sensory environment.

\section{Methods}

\section{Participants}

Forty healthy study volunteers were recruited from the University of Reading and screened for this present study. Four participants were excluded. One participant was missing questionnaire data and was unable to return to correct this. Two participants were excluded for excessive motion artifacts during resting state based on a cut-off of $2.5 \mathrm{~mm}$ for peak movement artifacts $(7 \mathrm{~mm} \& 10 \mathrm{~mm}$, respectively) and one participant was excluded because of insufficient scan data quality due to large artifacts which couldn't be corrected and impacted on group analysis. This left a final sample of 36 participants (14 Female; mean age 22.83 years, $S D=5.41)$. Participants were excluded if they had active or historical chronic pain disorder diagnoses, current instances of acute pain (e.g. serious cuts or bruises), current substance abuse or uncorrected visual impairment. All participants also confirmed that they had never practiced mindfulness meditation. All participants provided informed consent prior to the study, and the study was approved by the University of Reading's University Research Ethics Committee. 


\section{Materials}

Thermal Stimulation: Noxious heat stimulation was generated by a MEDOC Pathway system (Medoc Medical Systems, Haifa, Israel) using a 30x30 Peltier thermode, applied to the lower right calf, which was placed into a customised wooden leg rest.

Questionnaires: Pain catastrophising was measured using the Pain Catastrophising Scale (PCS) [50]. The scale includes 13 items scored on a 5 point Likert-Type scale $(0=$ not at all, to $4=$ all of the time). Total scores were used in this study, with higher scores indicating higher catastrophising. Trait Mindfulness was measured using the Five Facet Mindfulness Questionnaire (FFMQ) [2]. The scale includes 39 items scored on a 5 point Likert-type scale ( $1=$ never or rarely true to $5=$ very often or always true). Higher scores represent higher levels of mindfulness. The FFMQ is the most widely studied measure of trait mindfulness [44] and possesses good psychometric properties $[1,5]$.

\section{Design}

The current experiment is part of a larger study investigating the link between neural and psychophysical measures and cognitive/emotional modulation of pain, which took place over four sessions, counterbalanced for order of completion. Firstly, participants completed the FFMQ and PCS via a secure third-party website (https://www.surveymonkey.com). After this, they attended the first session, a psychophysical assessment, followed by a neuroimaging session that took place no more than seven days after the initial session. The final two sessions examined cognitive and emotional pain modulation tasks unrelated to this study, which are not described further.

\section{Procedure}

Pain Threshold Assessment: We used two assessments to measure pain threshold. Both methods utilised a visual analogue scale (VAS) [39], displayed on a laminated A4 piece of 
paper. The minimum rating of 0 was described as "No pain at all" and the highest anchor of 10 was anchored with "most intense pain imaginable". The first assessment was via method of limits, starting at a $32^{\circ} \mathrm{C}$ baseline rising by $0.5^{\circ} \mathrm{C} / \mathrm{s}$ until the participant indicated that the stimulus was painful. There were 4 trials with an 8 s inter-stimulus interval. The average of the final 3 trials was taken as the limits threshold.

In the method of levels design, stimuli were initiated at a $32^{\circ} \mathrm{C}$ baseline, and increased by $8 \% \mathrm{~s}$ to a $40^{\circ} \mathrm{C}$ peak, where it remained for $8 \mathrm{~s}$. The participant was primed to indicate on a mouse whether the stimulus was painful. If they indicated "no", the subsequent trial increased by $2^{\circ} \mathrm{C}$. If they indicated yes, the temperature decreased at half the interval size and the same pattern continued until 4 reversals of direction had been reached, and which point the programme terminated. The average of the final two trials was used as the individual's levels threshold. The products of each threshold method were highly correlated $(r(37)=.786, p<.01)$, and the mean of the limits and levels threshold was used as the participant's threshold.

Behavioural Data Analysis: Pearson's correlations were used to examine associations between trait mindfulness, pain catastrophising and pain threshold. Significance was set at $\mathrm{p}<.05$. All statistical analysis was completed using SPSS.

fMRI Acquisition: Functional images were acquired using a 3T Siemens TRIO MRI scanner with a 32-channel head coil. The MRI session consisted of an initial localiser, followed by a 10-minute resting-state scan. Two runs of an event-related functional task (not described here) were completed, either side of a T1-weighted structural scan. A field map was collected as the last item within the scan protocol. For resting-state, participants were instructed to close their eyes and not to move. The protocol consisted of 30 interleaved 3.5mm sagittal $\mathrm{T}^{*}$ weighted gradient echo echo-planar imaging (EPI) slices. All functional 
images were prepared as 4D NIFTI images $\left(T E=28 \mathrm{~ms}\right.$, TR $=2000 \mathrm{~ms}$, flip angle $=90^{\circ}, 1 \mathrm{~mm}$ interslice gap; 128x128 matrix, field-of-view (FOV)=240mm).

Anatomical images were then acquired within an 8-minute T1-weighted inversion recovery fast gradient echo-high resolution structural scan (176 volumes, TE=2.9ms, TR=2000ms, $\mathrm{FA}=90^{\circ}$, voxel size $=1 \times 1 \times 1 ; 256 \times 256$ matrix, $\left.\mathrm{FOV}=250 \mathrm{~mm}\right)$.

\section{fMRI Data Analysis}

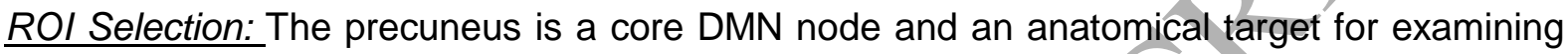
DMN processing $[47,55]$. A region within the precuneus cortex was selected for seed-based whole brain connectivity analysis [48]. For the purpose of preparing this seed region, a $2 \mathrm{~mm}$ sphere was projected around the co-ordinates supplied $(X=-8, Y=-64, Z=18)$. As there were no hypothesised differences in relation to lateralisation, these seed co-ordinates were bilateralised when creating the seed.

Pre-Processing: Analysis was performed using the FSL analysis package (FSL Version 6.00; www.fmrib.ox.ac.uk/fsl),[23]. The Brain Extraction Tool (BET)[49] was used for skull stripping. The first 5 volumes were removed to allow for signal equilibration effects. An interleaved slice-timing correction was applied. Data was smoothed with a $5 \mathrm{~mm}$ full-width half-maximum (FWHM) Gaussian spatial smoothing kernel. MCFLIRT was used for motion correction and data were visually inspected for motion artifacts and registration accuracy [22].

FSL's FAST module [63] was used to segment gray matter from white matter (WM) and cerebrospinal fluid (CSF). WM and CSF maps were thresholded at 0.99 to minimize overlapping signal from gray matter prior to time series extraction. Time series of WM and CSF were entered into a general linear model along with motion parameters. Residuals from this nuisance analysis were normalised and bandpass filtered $(0.1 / 0.01 \mathrm{~Hz})$ to reduce the 
influence of low frequency drift (inclusive of scanner drift), and high frequency interference such as cardiac or respiratory confounds.

Resting State Analysis: The mean time series of all voxels within the precuneus seed region were extracted and included as a regressor in a whole-brain functional connectivity analysis. Contrast images were then entered into a second higher level analyses in which participant's demeaned FFMQ scores were entered as a regressor. This analysis examined brain regions where connectivity of the precuneus was significantly correlated with trait mindfulness. All fMRI analyses were corrected for multiple comparisons using Gaussian random field theory $(Z<2.3 ; p<.05)$.

To ensure that results were not driven by outliers, and to investigate whether connectivity patterns associated with trait mindfulness were also associated with pain reactivity, parameter estimates from regions where functional connectivity with the precuneus was significantly correlated with trait mindfulness were extracted using FEATQuery. To allow for more anatomically specific inferences, these clusters were constrained using meta-analysis masks generated from the NeuroSynth database [56]. In line with our hypotheses that connectivity patterns associated with trait mindfulness would be consistent with a tendency to attend to sensory aspects of pain without emotional evaluation, the map of regions positively correlated with trait mindfulness were masked with a reverse inference mask of the terms "pain" and "painful", while the map of regions negatively associated with trait mindfulness was masked with a mask of the terms "emotion" and "emotional". While these masks are not specific to the named processes, the advantage of this approach is that it constrains findings to areas known to be relevant to these processes. Although the use of these meta-analysis masks aided inference, results were not dependent on their use, as similar results were obtained from the larger unmasked clusters. 


\section{Results}

Trait Mindfulness, Pain Catastrophising \& Threshold: Higher trait mindfulness was significantly associated with higher pain thresholds $(r=.43, p=.004)$ and lower pain catastrophising $(r=-.59, p<.01)$ (Figure 1). Pain catastrophising and pain threshold were not significantly correlated $(r=-.22, p=.103)$.

To examine the overlap in predictive variance, we included both threshold and pain catastrophising in a regression model with FFMQ as dependent measure (Table 1). Pain catastrophising \& threshold were significantly predictive of trait mindfulness. $(F(2,33)=12.96$, $\mathrm{p}<0.01)$. Both variables remained significantly associated with $F F M Q$ within the model.

Seed-based DMN Connectivity: A thresholded map of precuneus functional connectivity confirmed that the precuneus ROI effectively probed the DMN (Figure 2)

There were two significant clusters of activation where precuneus connectivity was positively correlated with trait mindfulness. These included the primary and secondary somatosensory cortices (cluster 1\&2; Figure 2 \& Table 2), as well as adjacent areas within the precuneus cluster 7). Due to the bilateral symmetry of the two positively correlated clusters, these were merged to a form a single bilateral cluster for the purpose of extraction. The association between trait mindfulness and connectivity between precuneus and somatosensory cortices (BA1, BA2, BA3) are plotted in Figure 3.

There were five clusters where precuneus connectivity was negatively correlated with trait mindfulness, including the medial prefrontal cortex (mPFC; cluster 3), confirming our hypothesis that trait mindfulness would be associated with reduced connectivity of key DMN nodes. The association between trait mindfulness and connectivity between these DMN nodes is plotted in Figure 4. 
Connectivity between our precuneus seed and both the somatosensory (Figure 5) and prefrontal clusters (Figure 6) were significantly correlated with pain threshold $(r=.46, p<.01$; $r=-.34, p=.02$ respectively $)$ and pain catastrophising $(r=.50, p<.01 ; r=.31, p=.03$ respectively).

\section{Discussion}

Numerous studies have shown that mindfulness practice attenuates pain $[10,11,34,42,60]$ but less is known about whether dispositional mindfulness confers the ability to cope with pain in the absence of training or explicit mindful practice. This study examined the relationship between dispositional mindfulness and pain reactivity, and the neural mechanisms that underlie these relationships. As hypothesised, trait mindfulness was associated with higher pain thresholds and lower pain catastrophising. These findings are similar to observations following increases in mindfulness via training $[27,45,54,58]$. Mindfulness based interventions and long term contemplative practice are associated with increases in sensory pain thresholds $[27,41,45,58]$, as well as decreases in maladaptive pain-related cognitions, such as pain catastrophising [45,54]. It is worth nothing that pain catastrophising was not significantly correlated with pain threshold. This surprising result may reflect the use of a controlled, experimental pain stimulus, in a context where participants are reassured that the stimulus presents no threat of damage, and can be stopped immediately at any time. Regardless of the explanation, the fact that trait mindfulness correlates with both variables even though they don't correlate with each other reinforces the assertion that it reflects both sensory and emotional responsivity. This is further supported by the regression model, where both threshold and catastrophising were significantly associated with trait mindfulness, even after accounting for shared variance.

We also found that higher trait mindfulness was associated with stronger functional connectivity of a key default mode network node (precuneus) and somatosensory cortices, as well as weaker connectivity between the precuneus and another DMN node, the medial 
prefrontal cortex. Previous research has linked meditative practice with deactivation of these DMN nodes $[6,7,15,51]$. This deactivation is associated with a decreased tendency towards maladaptive cognitive processes like rumination and mind-wandering, where attention is drawn away from the present moment [3,29,30,51]. Our findings suggest that trait mindfulness might function as a marker for these processes, even in the absence of a previous mindfulness based intervention or long term meditative practice. Taken together with the positive correlation observed between trait mindfulness and functional connectivity of DMN and somatosensory cortices, these findings are consistent with decoupling of sensory and evaluative processes and with characterisation of mindfulness as "...a state of awareness that attends towards immediate experience and is free of rumination or apprehension" [4].

To investigate whether these patterns of activation characterise pain reactivity, we tested whether connectivity of precuneus with sensory/salience and emotion/evaluative regions was associated with individuals' sensory and affective pain responses. Consistent with sensory/affective decoupling described in interventional literature $[16,17,25]$ we found that connectivity between the precuneus and both somatosensory cortices and mPFC were significantly correlated with pain threshold and pain catastrophising. We have previously proposed that meditative training influences pain perception through a unique neural mechanism, characterized by increased activation of sensory/salience related regions and decreased activation in areas involved in affective/evaluative responses [43,62], consistent with increased attention to sensory aspects of pain but reduction in negative cognitive and affective responses. Our findings are in line with this proposed mechanism, but with two critical distinctions. First, we observed correlations between pain reactivity and resting state functional connectivity, rather than pain-evoked neural responses. Second, these associations were found in individuals prior to any mindfulness training. Together, these findings suggest that trait mindfulness might function as a marker for dispositional individual differences in the ability to cope with pain and that the mechanism of these individual 
differences is similar to that observed in individuals with both short and long term mindfulness training. It is important to note that independent replication is necessary to more accurately characterize the size and reliability of these effects. Also, the addition of a taskbased design would allow us to more directly characterize the specific processes that these patterns of connectivity are engaging in, and how they contribute to the ability to cope with pain.

A dispositional marker of pain reactivity, particularly one like trait mindfulness that does not rely on previous experience with pain (as constructs like pain catastrophising do) could have clinical utility. While the FFMQ does not query pain behaviour, or current mental health symptoms, our findings suggest that mindfulness could provide information about how individuals cope with pain. As such, it could be used to identify individuals who might benefit from additional pain coping training in the wake of a painful event such as surgery, where poor coping can confer increased risk of developing chronic pain. These data do not speak to whether mindfulness training would be effective in such a setting, to the efficacy of mindfulness interventions more generally or to whether this decoupling process would apply to patients with long-term chronic pain. Instead, we demonstrate that even in the absence of any kind of formal mindfulness training, practice or intervention, trait mindfulness is associated with individual differences in pain responsivity. A critical area for further research is understanding the relationship between trait mindfulness and responsiveness to mindfulness-based interventions. Repeated increases in state mindfulness can lead to increased trait mindfulness [26], indicating that trait mindfulness is not immutable. It is less clean however, whether high or low trait mindfulness is associated with optimal response to mindfulness based interventions. Preliminary research indicates that participants high in trait mindfulness experience greater increases in mindfulness, subjective well-being and empathy in response to a mindfulness intervention, with larger decreases in perceived stress after a year [46]. The generalizability of these findings to pain responsivity, however, has yet to be investigated. 
In summary, this study took a novel approach to studying mindfulness by examining dispositional mindfulness in individuals naïve to mindfulness-based practices or interventions. We demonstrated that even in the absence of any kind of formal mindfulness training, practice or intervention, trait mindfulness is associated with individual differences in pain responsivity, and characteristic patterns of functional connectivity. Mirroring the interventional literature, we found that trait mindfulness was positively associated with pain threshold, and inversely associated with pain catastrophising. Resting state analysis revealed that this pattern of pain reactivity was associated with lower connectivity of the default mode network and greater synchronization of the DMN with somatosensory regions, consistent with a disposition to attend to immediate sensory aspects of experience and disengage from ruminative and evaluative cognitive processes.

\section{References}

[1] Baer RA, Smith GT, Lykins E, Button D, Krietemeyer J, Sauer S, Walsh E, Duggan D, Williams JMG. Construct validity of the five facet mindfulness questionnaire in meditating and nonmeditating samples. Assessment 15:329-42, 2008. doi:10.1177/1073191107313003.

[2] Baer RA, Smith GT, Hopkins J, Toney L. Using Self-Report Assessment Methods to Explore Facets of Mindfulness. Assessment 13:27-45, 2006.

[3] Baliki MN, Geha PY, Apkarian AV., Chialvo DR. Beyond Feeling: Chronic Pain Hurts the Brain, Disrupting the Default-Mode Network Dynamics. J. Neurosci. 28:13981403, 2008. doi:10.1523/JNEUROSCI.4123-07.2008.

[4] Bishop SR, Lau M, Shapiro S, Carlson L, Anderson ND, Carmody J, Segal ZV, Abbey S, Speca M, Velting D, Devins G. Mindfulness: A proposed operational definition. Clin. Psychol. Sci. Pract. 11:230-241, 2004.

[5] Bohlmeijer E, ten Klooster PM, Fledderus M, Veehof M, Baer R. Psychometric 
properties of the five facet mindfulness questionnaire in depressed adults and development of a short form. Assessment 18:308-320, 2011.

doi:10.1177/1073191111408231.

[6] Brefczynski-Lewis JA, Lutz A, Schaefer HS, Levinson DB, Davidson RJ. Neural correlates of attentional expertise in long-term meditation practitioners. Proc. Natl. Acad. Sci. 104:11483-11488, 2007. doi:10.1073/pnas.0606552104.

[7] Brewer JA, Worhunsky PD, Gray JR, Tang Y-Y, Weber J, Kober H. Meditation experience is associated with differences in default mode network activity and connectivity. Proc. Natl. Acad. Sci. 108:20254-20259, 2011. doi:10.1073/pnas.1112029108.

[8] Brown CA, Jones AK. Psychobiological correlates of improved mental health in patients with musculoskeletal pain after a mindfúlness-based pain management program. Clin. J. Pain 29:233-244, 2013.

[9] Cavada C, Compañy T, Tejedor J, Cruz-Rizzolo RJ, Reinoso-Suárez F. The anatomical connections of the macaque monkey orbitofrontal cortex. A review. Cereb. cortex 10:220-242, 2000. doi:10.1093/cercor/10.3.220.

[10] Cherkin DC, Sherman KJ, Balderson BH, Cook AJ, Anderson ML, Hawkes RJ, Hansen KE, Turner JA. Effect of Mindfulness-Based Stress Reduction vs Cognitive Behavioral Therapy or Usual Care on Back Pain and Functional Limitations in Adults With Chronic Low Back Pain. J. Am. Med. Assoc. 315:1240, 2016. doi:10.1001/jama.2016.2323.

[11] Chiesa/A, Serretti A. Mindfulness-based interventions for chronic pain: a systematic review of the evidence. J. Altern. Complement. Med. 17:83-93, 2011. doi:10.1089/acm.2009.0546.

[12] Christoff K, Gordon AM, Smallwood J, Smith R, Schooler JW. Experience sampling during $\mathrm{fMRI}$ reveals default network and executive system contributions to mind wandering. Proc. Natl. Acad. Sci. 106:8719-8724, 2009.

[13] Creswell JD, Taren AA, Lindsay EK, Greco CM, Gianaros PJ, Fairgrieve A, Marsland 
AL, Brown KW, Way BM, Rosen RK, Ferris JL. Alterations in resting state functional connectivity link mindfulness meditation with reduced interleukin-6: a randomized controlled trial. Biol. Psychiatry 1-9, 2016. doi:10.1016/j.biopsych.2016.01.008.

[14] Dickenson J, Berkman ET, Arch J, Lieberman MD. Neural correlates of focused attention during a brief mindfulness induction. Soc. Cogn. Affect. Neurosci. 8:40-47, 2013.

[15] Farb NAS, Segal Z V., Mayberg H, Bean J, Mckeon D, Fatima Z, Anderson AK. Attending to the present: Mindfulness meditation reveals distinct neural modes of selfreference. Soc. Cogn. Affect. Neurosci. 2:313-322, 2007.

[16] Gard T, Hölzel BK, Sack AT, Hempel H, Lazar SW, Vaitl D, Ott U.Pain attenuation through mindfulness is associated with decreased cognitive control and increased sensory processing in the brain. Cereb. Cortex 22:2692-2702, 2012.

[17] Grant JA, Courtemanche J, Duerden EG, Duncan GH, Rainville P. Cortical thickness and pain sensitivity in zen meditators. Emotion 10:43-53, 2010. doi:10.1037/a0018334.

[18] Grant JA, Courtemanche J, Rainville P. A non-elaborative mental stance and decoupling of executive and pain-related cortices predicts low pain sensitivity in Zen meditators. Pain 152:150-156, 2011. doi:10.1016/j.pain.2010.10.006.

[19] Grant JA, Rainville P. Pain sensitivity and analgesic effects of mindful states in zen meditators: A cross-sectional study. Psychosom. Med. 71:106-114, 2009.

[20] Hasenkamp/W, Wilson-Mendenhall CD, Duncan E, Barsalou LW. Mind wandering and attention during focused meditation: A fine-grained temporal analysis of fluctuating cognitive states. Neuroimage 59:750-760, 2012. doi:10.1016/j.neuroimage.2011.07.008.

[21] Hölzel BK, Lazar SW, Gard T, Schuman-Olivier Z, Vago DR, Ott U. How Does Mindfulness Meditation Work? Proposing Mechanisms of Action From a Conceptual and Neural Perspective. Perspect. Psychol. Sci. 6:537-559, 2011. doi:10.1177/1745691611419671. 
[22] Jenkinson M, Bannister P, Brady M, Smith S. Improved optimization for the robust and accurate linear registration and motion correction of brain images. Neuroimage $17: 825-841,2002$.

[23] Jenkinson M, Beckmann CF, Behrens TEJ, Woolrich MW, Smith SM. Fsl. Neuroimage 62:782-790, 2012.

[24] Kabat-Zinn J. An outpatient program in behavioral medicine for chronic pain patients based on the practice of mindfulness meditation: Theoretical considerations and preliminary results. Gen. Hosp. Psychiatry 4:33-47, 1982.

[25] Kam JWY, Handy TC. The neurocognitive consequences of the wandering mind: a mechanistic account of sensory-motor decoupling. Front. Psychol. 4:1-13, 2013. doi:10.3389/fpsyg.2013.00725.

[26] Kiken LG, Garland EL, Bluth K, Palsson OS, Gaylord SA. From a state to a trait: Trajectories of state mindfulness in meditation during intervention predict changes in trait mindfulness. Pers. Individ. Dif. 81:41-46, 2015.

[27] Kingston J, Chadwick P, Meron D, Skinner TC. A pilot randomized control trial investigating the effect of mindfulness practice on pain tolerance, psychological wellbeing, and physiological activity. J. Psychosom. Res. 62:297-300, 2007.

[28] Kucyi A, Davis KD. Dynamic functional connectivity of the default mode network tracks daydreaming. Neuroimage 100:471-480, 2014. doi:10.1016/j.neuroimage.2014.06.044.

[29] Kucyi A, Davis KD. The dynamic pain connectome. Trends Neurosci. 38:86-95, 2015. doi:10.1016/j.tins.2014.11.006.

[30] Kucyi A, Moayedi M, Weissman-Fogel I, Goldberg MB, Freeman BV, Tenenbaum HC, Davis KD. Enhanced Medial Prefrontal-Default Mode Network Functional Connectivity in Chronic Pain and Its Association with Pain Rumination. J. Neurosci. 34:3969-3975, 2014. doi:10.1523/JNEUROSCI.5055-13.2014.

[31] Ludwig DS, Kabat-Zinn J. Mindfulness in Medicine. JAMA 300:1350, 2008. doi:10.1001/jama.300.11.1350. 
[32] Lutz A, McFarlin DR, Perlman DM, Salomons TV, Davidson RJ. Altered anterior insula activation during anticipation and experience of painful stimuli in expert meditators. Neuroimage 64:538-546, 2013. doi:10.1016/j.neuroimage.2012.09.030.

[33] McCracken LM, Gauntlett-Gilbert J, Vowles KE. The role of mindfulness in a contextual cognitive-behavioral analysis of chronic pain-related suffering and disability. Pain 131:63-69, 2007.

[34] Morone NE, Greco CM, Moore CG, Rollman BL, Lane B, Morrow LA, Glynn NW, Weiner DK. A Mind-Body Program for Older Adults With Chronic Low Back Pain. JAMA Intern. Med. 176:329, 2016. doi:10.1001/jamainternmed.2015.8033.

[35] Mun CJ, Okun MA, Karoly P. Trait mindfulness and catastrophising as mediators of the association between pain severity and pain-related impairment. Pers. Individ. Dif. 66:68-73, 2014. doi:10.1016/j.paid.2014.03.016.

[36] Paul NA, Stanton SJ, Greeson JM, Smoski MJ, Wang L. Psychological and neural mechanisms of trait mindfulness in reducing depression vulnerability. Soc. Cogn. Affect. Neurosci. 8:56-64, 2013.

[37] Perlman DM, Salomons TV, Davidson RJ, Lutz A. Differential effects on pain intensity and unpleasantness of two meditation practices. Emotion 10:65-71, 2010. doi:10.1037/a0018440.

[38] Petter M, Chambers CT, McGrath PJ, Dick BD. The role of trait mindfulness in the pain experience of adolescents. J. Pain 14:1709-1718, 2013. doi:10.1016/j.jpain.2013.08.015.

[39] Price DD, Bush FM, Long S, Harkins SW. A comparison of pain measurement characteristics of mechanical visual analogue and simple numerical rating scales. Pain 56:217-226, 1994.

[40] Prins B, Decuypere A, Van Damme S. Effects of mindfulness and distraction on pain depend upon individual differences in pain catastrophising: An experimental study. Eur. J. Pain 18:1307-1315, 2014.

[41] Reiner K, Granot M, Soffer E, Lipsitz JD. A Brief Mindfulness Meditation Training 
Increases Pain Threshold and Accelerates Modulation of Response to Tonic Pain in an Experimental Study. Pain Med. 17:628-635, 2016.

[42] Reiner K, Tibi L, Lipsitz JD. Do mindfulness-based interventions reduce pain intensity? A critical review of the literature. Pain Med. 14:230-42, 2013. doi:10.1111/pme.12006.

[43] Salomons TV, Kucyi A. Does Meditation Reduce Pain through a Unique Neural Mechanism? J. Neurosci. 31:12705-12707, 2011. doi:10.1523/JNEUROSCI.284311.2011.

[44] Sauer S, Walach H, Schmidt S, Hinterberger T, Lynch S, Büssíng A, Kohls N. Assessment of Mindfulness: Review on State of the Art. Mindfulness (N. Y). 4:3-17, 2013.

[45] Schütze R, Rees C, Preece M, Schütze M. Low mindfulness predicts pain catastrophising in a fear-avoidance model of chronic pain. Pain 148:120-127, 2010. doi:10.1016/j.pain.2009.10.030.

[46] Shapiro SL, Brown KW, Thoresen C, Plante TG. The moderation of Mindfulnessbased stress reduction effects by trait mindfulness: Results from a randomized controlled trial. J. Clin. Psychol. 67:267-277, 2011.

[47] Sheline YI, Barch DM, Price JL, Rundle MM, Vaishnavi SN, Snyder AZ, Mintun MA, Wang S, Coalson RS, Raichle ME. The default mode network and self-referential processes in depression. Proc. Natl. Acad. Sci. 106:1942-1947, 2009. doi:10.1073/pnas.0812686106.

[48] Sheline YI, Price JL, Yan Z, Mintun MA. Resting-state functional MRI in depression unmasks increased connectivity between networks via the dorsal nexus. Proc. Natl. Acad. Sci. 107:11020-11025, 2010. doi:10.1073/pnas.1000446107.

[49] Smith SM. Fast robust automated brain extraction. Hum. Brain Mapp. 17:143-155, 2002.

[50] Sullivan M, Bishop S, Pivik J. Pain Catastrophising Scale. Psychol. Assess. 7:524532, 1995. 
[51] Taylor VA, Daneault V, Grant J, Scavone G, Breton E, Roffe-vidal S, Courtemanche J, Lavarenne AS, Marrelec G, Benali H, Beauregard M. Impact of meditation training on the default mode network during a restful state. Soc. Cogn. Affect. Neurosci. 8:414, 2013.

[52] Taylor VA, Grant J, Daneault V, Scavone G, Breton E, Roffe-Vidal S, Courtemanche J, Lavarenne AS, Beauregard M. Impact of mindfulness on the neural responses to emotional pictures in experienced and beginner meditators. Neuroimage 57:15241533, 2011. doi:10.1016/j.neuroimage.2011.06.001.

[53] Teixeira $\mathrm{E}$. The effect of mindfulness meditation on painful diabetic peripheral neuropathy in adults older than 50 years. Holist. Nurs. Pract. 24:277-283, 2010. doi:10.1097/HNP.0b013e3181f1add2.

[54] Turner JA, Anderson ML, Balderson BH, Cook AJ, Sherman KJ, Cherkin DC. Mindfulness-based stress reduction and cognitive behavioral therapy for chronic low back pain. Pain 157:2434-2444, 2016. doi:10.1097/j.pain.0000000000000635.

[55] Utevsky AV, Smith DV, Huettel SA. Precuneus Is a Functional Core of the DefaultMode Network. J. Neurosci, 34:932-940, 2014. doi:10.1523/JNEUROSCI.422713.2014.

[56] Yarkoni T, Poldrack R, Nichols T. Large-scale automated synthesis of human functional neuroimaging data. Nat. Methods 8:665-670, 2011.

[57] Zeidan F. Mindfullness meditation-related pain relief: Evidence for unique brain mechanisms in the regulation of pain. Neurosci. Lett. 520:165-173, 2012. doi:10.1016/j.neulet.2012.03.082.

[58] Zeidan F, Gordon NS, Merchant J, Goolkasian P. The Effects of Brief Mindfulness Meditation Training on Experimentally Induced Pain. J. Pain 11:199-209, 2010. doi:10.1016/j.jpain.2009.07.015.

[59] Zeidan F, Grant JA, Brown CA, McHaffie JG, Coghill RC. Mindfulness meditationrelated pain relief: Evidence for unique brain mechanisms in the regulation of pain. Neurosci. Lett. 520:165-173, 2012. doi:10.1016/j.neulet.2012.03.082. 
[60] Zeidan F, Martucci KT, Kraft RA, Gordon NS, McHaffie JG, Coghill RC. Brain Mechanisms Supporting the Modulation of Pain by Mindfulness Meditation. J. Neurosci. 31:5540-5548, 2011. doi:10.1523/JNEUROSCI.5791-10.2011.

[61] Zeidan F, Martucci KT, Kraft RA, Gordon NS, McHaffie JG, Coghill RC. Brain Mechanisms Supporting the Modulation of Pain by Mindfulness Meditation. J. Neurosci. 31:5540-5548, 2011. doi:10.1523/JNEUROSCI.5791-10.2011.

[62] Zeidan F, Vago DR. Mindfulness meditation-based pain relief: a mechanistic account. Ann. N. Y. Acad. Sci. 1373:114-127, 2016.

[63] Zhang Y, Brady M, Smith S. Segmentation of brain MR images through a hidden Markov random field model and the expectation-maximization algorithm. IEEE Trans. Med. Imaging 20:45-57, 2001. 
Figure \& Table Titles

Figure 1

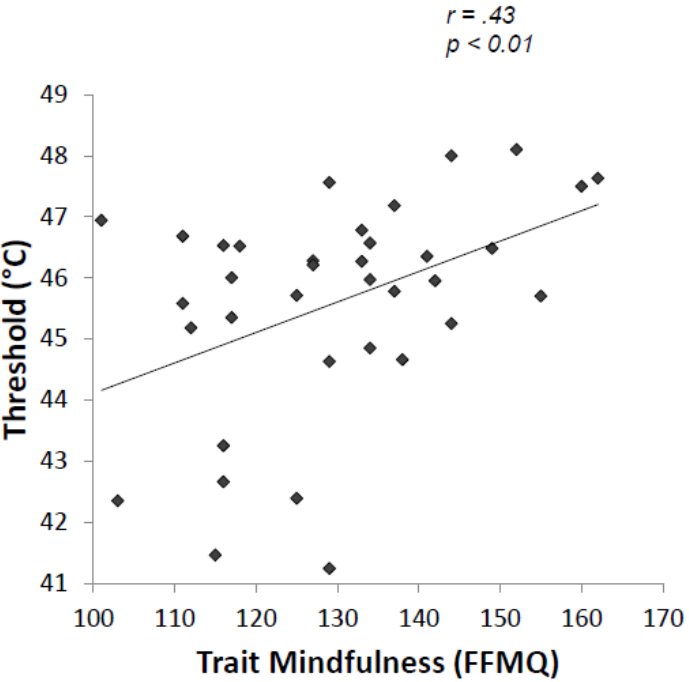

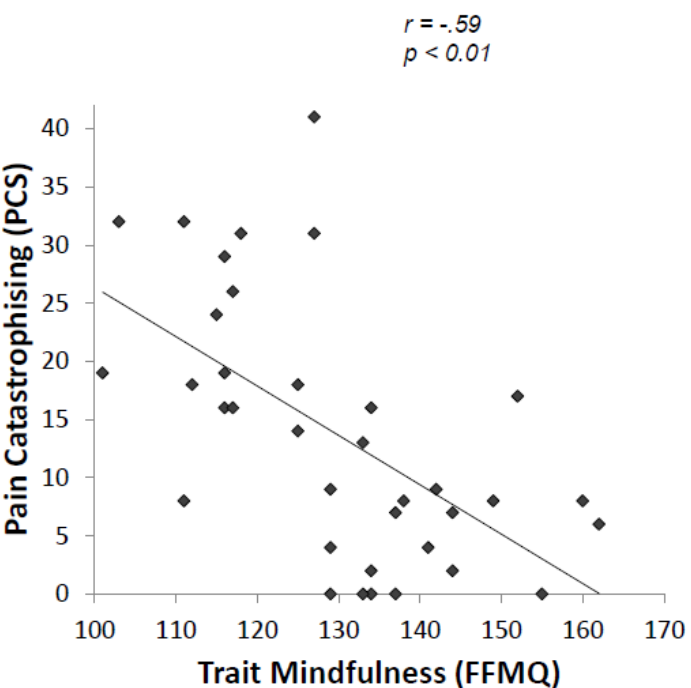

Figure 1: Association between trait mindfulness and threshold (left) and pain catastrophising scores (right)

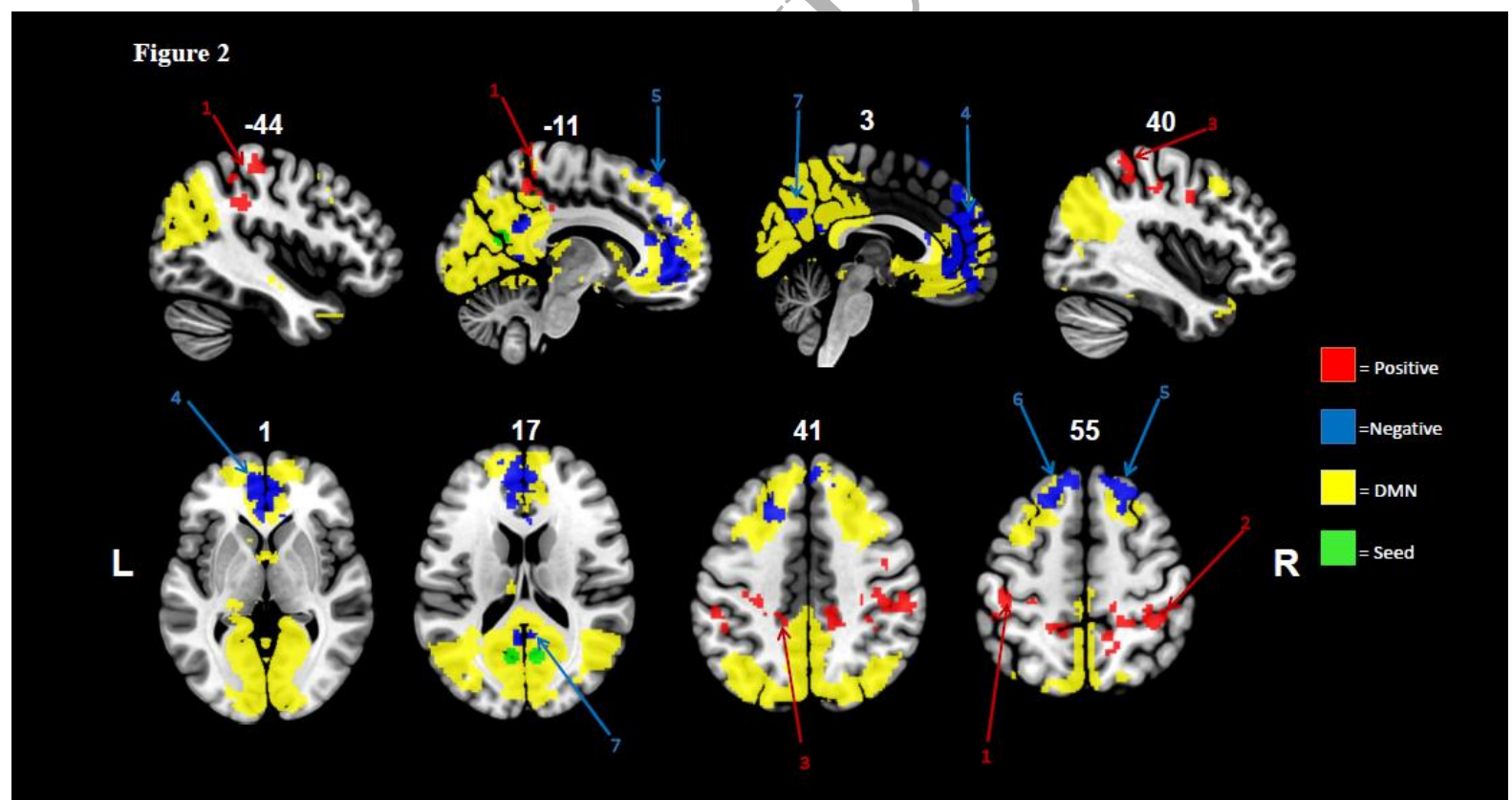

Figure 2: Isolated clusters (numbered in relation to clusters in table) in MNI space positively and negatively correlated with FFMQ scores (thresholded at $Z>2.3, p=.05$ corrected). Also displayed are DMN activation (yellow) and precuneus seed region (green). Images displayed according to neurological orientation conventions, with slice numbers 
Figure 3

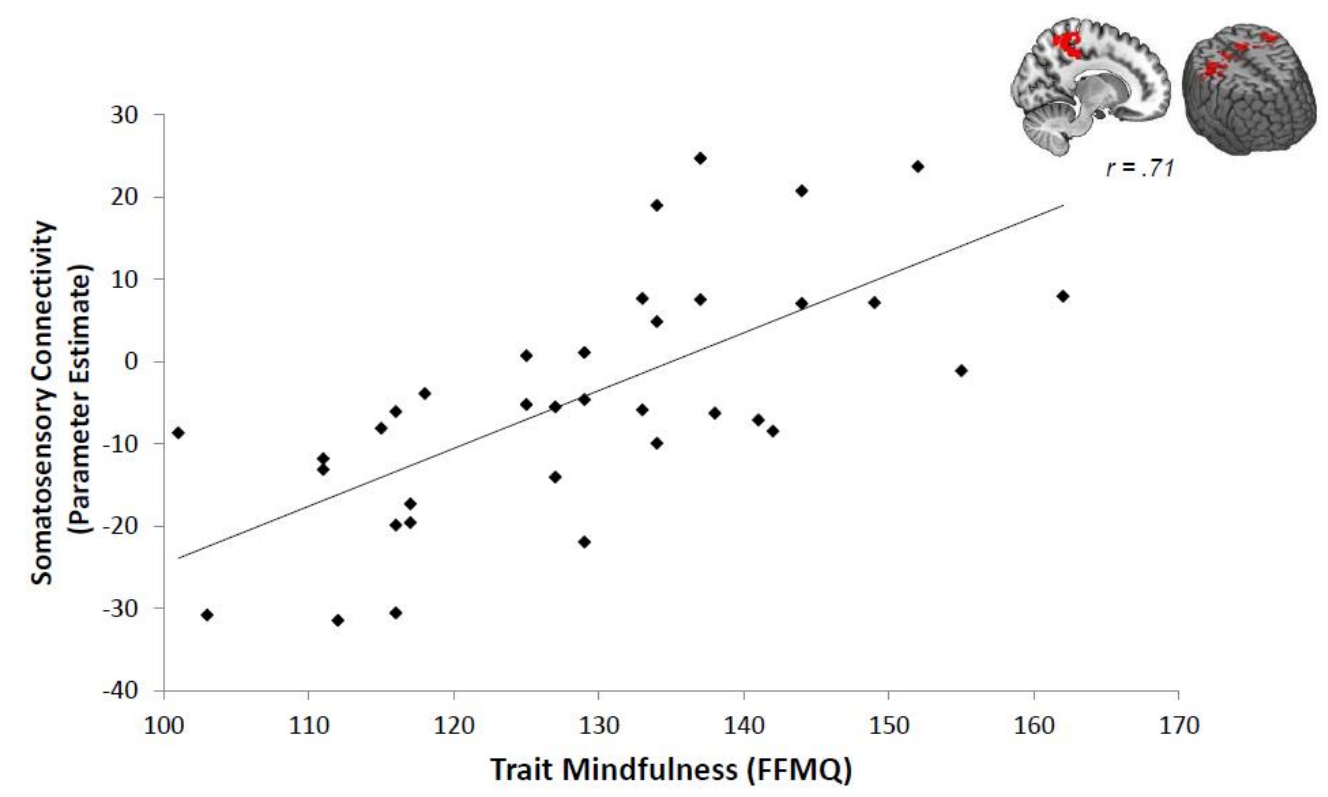

Figure 3: The relationship between trait mindfulness, and extracted mean time series connectivity values between the precuneus and somatosensory cluster

Figure 4

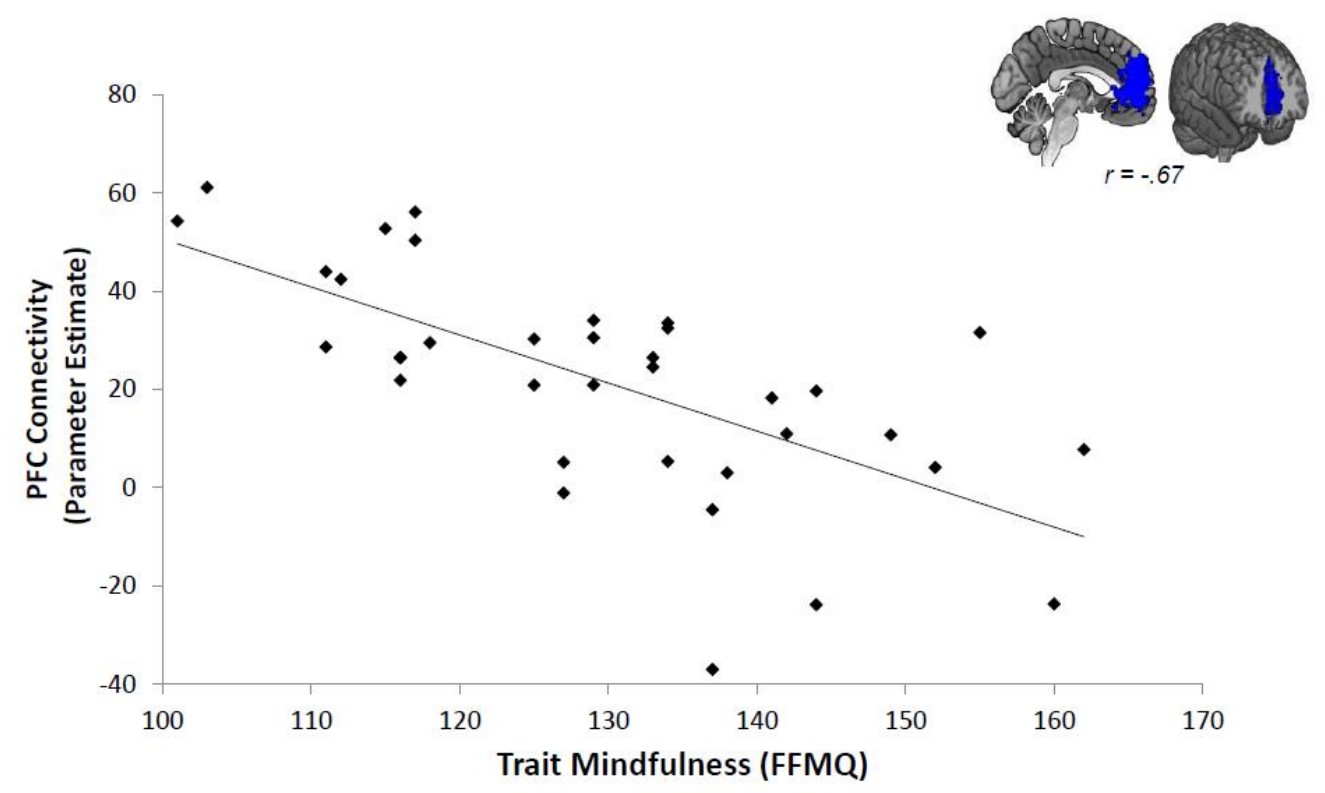

Figure 4: The relationship between trait mindfulness scores, and extracted mean time series/connectivity values between the precuneus and dorsal medial prefrontal cluster 
Figure 5
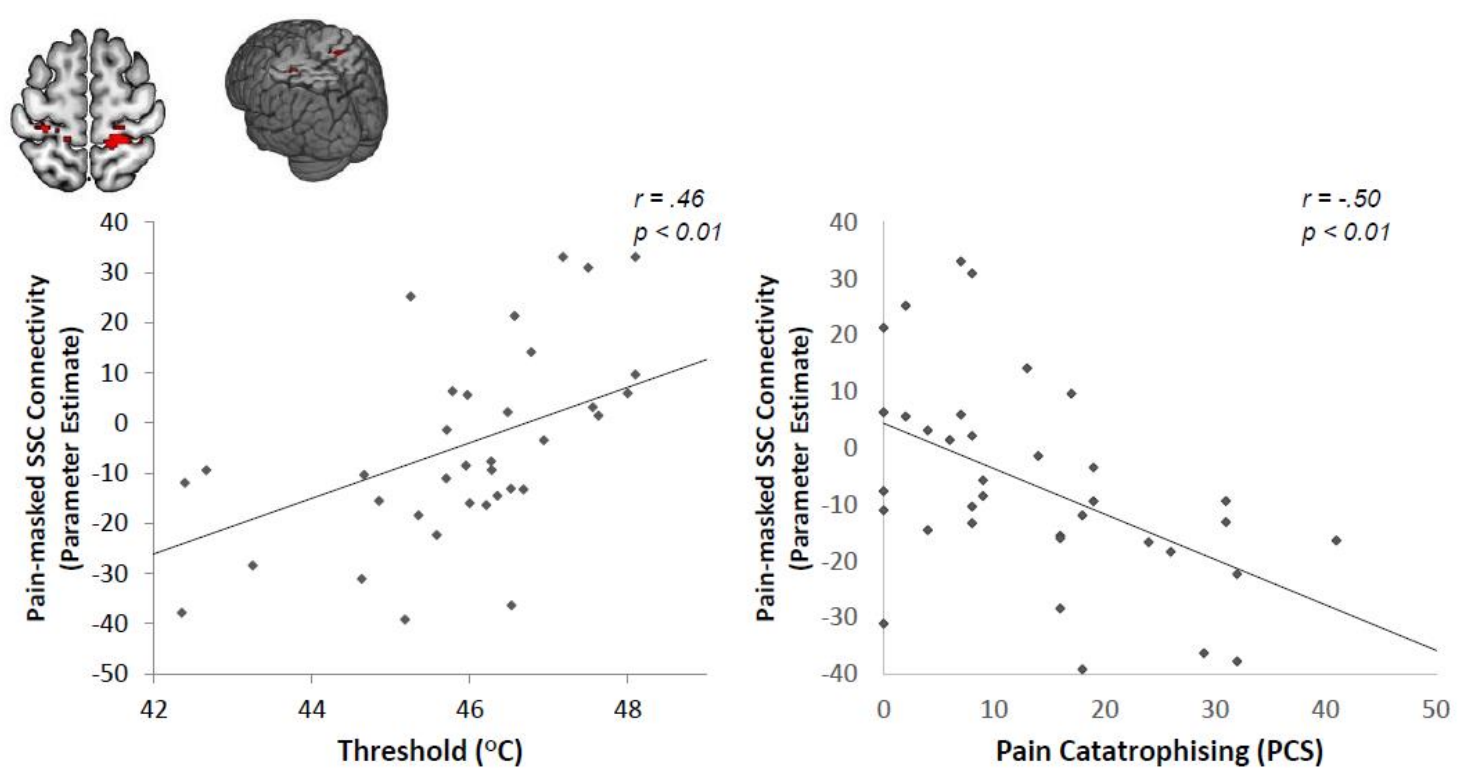

Figure 5: The relationship between pain catastrophising and stimulus threshold, and extracted mean time series connectivity values between the precuneus and painrelated regions of the bilateral somatosensory cluster

Figure 6
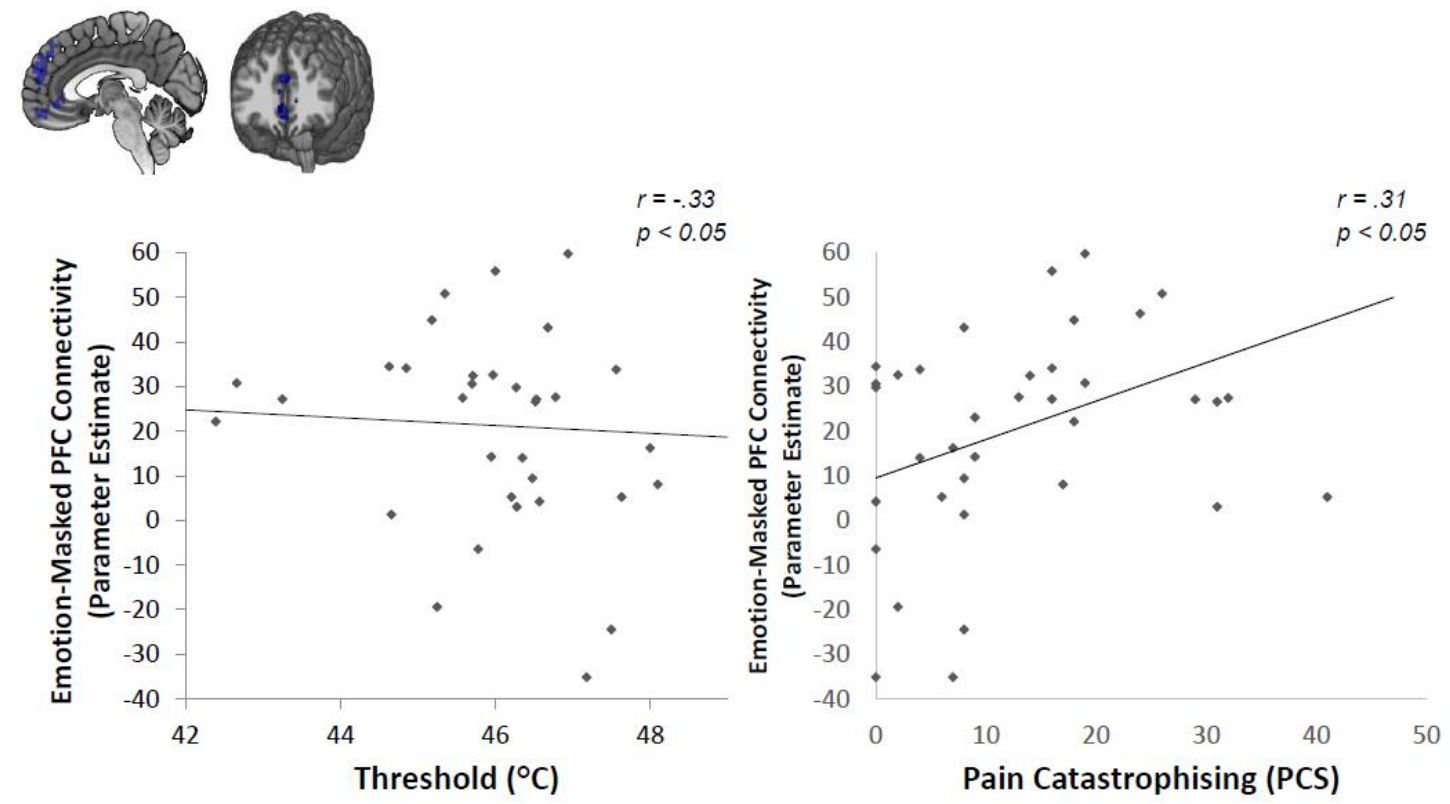

Figure 6: The relationship between pain catastrophising and stimulus threshold, and extracted mean time series connectivity values between the precuneus and painrelated regions of the prefrontal cortex cluster 
Table 1: Statistical output from behavioural regression model investigating the association between pain catastrophising and pain threshold on trait mindfulness

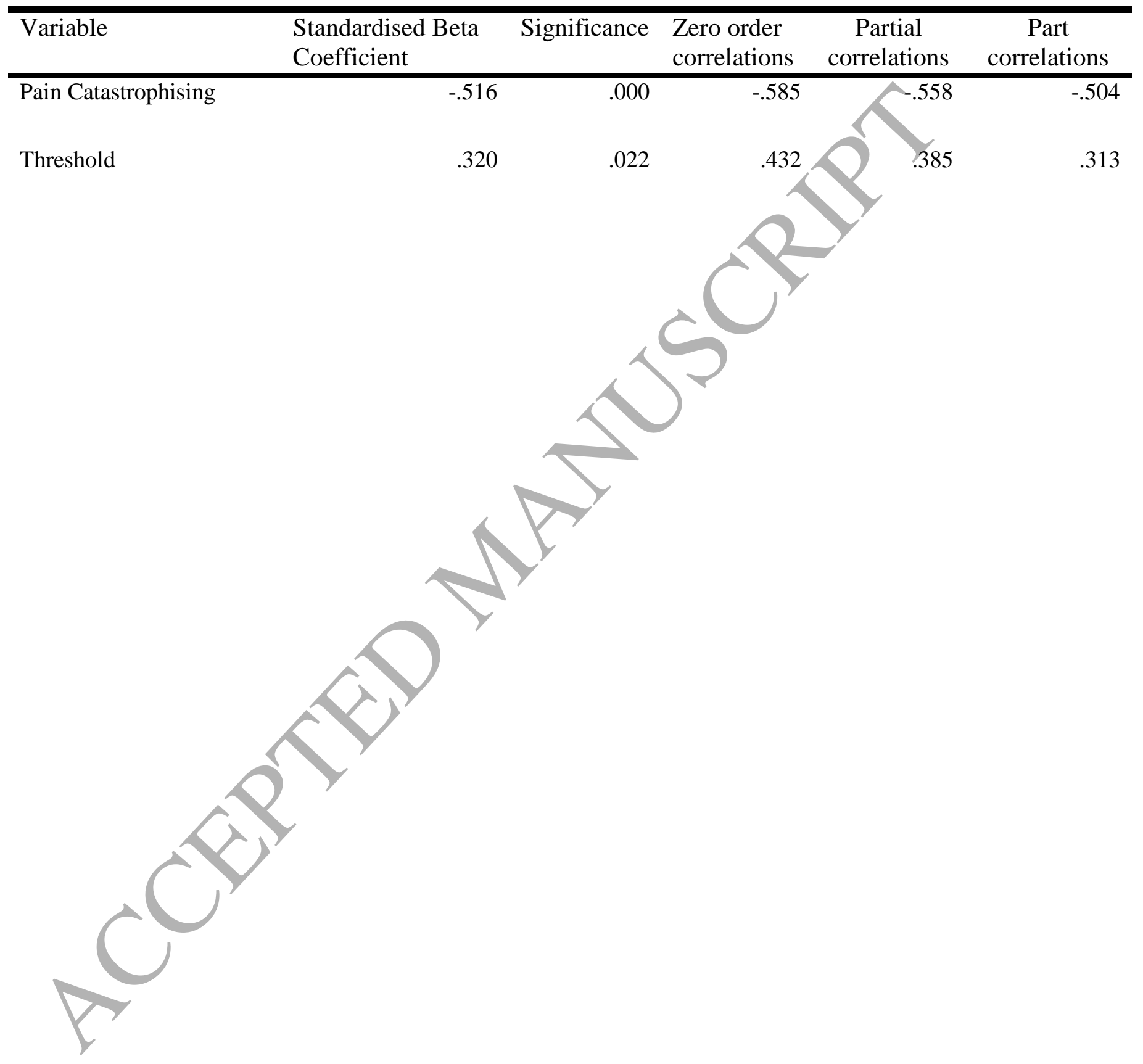


Table 2: Statistical peaks in MNI space of clusters associated with FFMQ scores

\begin{tabular}{|c|c|c|c|c|c|c|}
\hline \multirow[t]{2}{*}{ Anatomical Region } & \multirow[t]{2}{*}{$\begin{array}{l}\text { Brodmann } \\
\text { Areas }\end{array}$} & \multirow[t]{2}{*}{$\begin{array}{l}\text { Direction of } \\
\text { correlation }\end{array}$} & \multirow[t]{2}{*}{ Max Z-Stat } & \multicolumn{3}{|c|}{$\begin{array}{c}\text { MNI Co- } \\
\text { ordinates }(\mathrm{mm})\end{array}$} \\
\hline & & & & $X$ & $Y$ & $Z$ \\
\hline $\begin{array}{l}\text { 1. R. Parietal/ Motor/ Somatosensory } \\
\text { Cortex }\end{array}$ & $\begin{array}{l}\text { BA2, BA3a, } \\
\text { BA4, BA40 }\end{array}$ & Positive & 4.6 & 32 & -18 & 38 \\
\hline $\begin{array}{l}\text { 2. L. Parietal/ Motor/ Somatosensory } \\
\text { Cortex }\end{array}$ & $\begin{array}{l}\text { BA1, BA2, } \\
\text { BA3a, BA4, } \\
\text { BA7, BA40 }\end{array}$ & Positive & & -10 & -46 & 52 \\
\hline 3. L. Parietal/Somatosensory Cortex & $\begin{array}{l}\text { BA1, BA2, } \\
\text { BA3a, BA3b, } \\
\text { BA4, BA6 }\end{array}$ & & 3.28 & 14 & -32 & 44 \\
\hline $\begin{array}{l}\text { 4. Medial Prefrontal Cortex/ Perigenual } \\
\text { ACC }\end{array}$ & BA32, BA10 & Negative & 5.24 & -2 & 44 & 6 \\
\hline 5. L. Superior Frontal Gyrus/Pre-motor & BA6 & Negative & 4.13 & -10 & 36 & 54 \\
\hline 6. R. Superior Frontal Gyrus/Pre-motor & BA6 & Negative & 4.2 & 6 & 22 & 66 \\
\hline 7. Posterior Cingulate Cortex/Precuenus & BA29 & Negative & 4.65 & -10 & -50 & 26 \\
\hline
\end{tabular}

